\title{
Effect of Selected Range of Motion Exercise on Peripheral Circulation among Patients with Type II Diabetes Mellitus
}

\author{
Doaa Ali El Banna', Manal E. Fareed ${ }^{2}$, Seham Mohamed. Abd- \\ Elalem $^{3}$ \\ ${ }^{1}$ B.Sc. Nursing Science, ${ }^{2}$ professor of Medical Surgical Nursing, ${ }^{3}$ Assistant Professor of \\ Medical Surgical Nursing, Faculty of Nursing, Menoufia University
}

\begin{abstract}
Background: Diabetes mellitus (DM) has become a major chronic health problem worldwide resulting from defect in insulin action, secretion or both. It leads to macro vascular complication over long period such as cardiovascular disease, stroke and peripheral arterial disease. Purpose of the study: to determine the effect of selected range of motion exercise (Buerger- Allen Exercise) on peripheral circulation among patients with type II diabetes mellitus. Setting: Outpatient Medical Clinic at Shebin El Kom Teaching Hospital. Subjects: A consecutive sample of 100 adult patients were selected and divided alternatively into two equal groups: 50 patients for each group (study control). Instruments: Four instruments were used for data collection: Structured interview questionnaire, physiological instrument, ankle brachial index and observational checklist. Results: mean scores of ABPI in the right side improved from $0.74 \pm 0.06$ pre exercise to $1.0 \pm 0.13 \mathrm{after}$ four weeks of exercise implementation among study group versus $0.71 \pm 0.12$ and $0.71 \pm 0.11$ in the control one. While in the left side the mean scores of ABPI improved from $0.72 \pm 0.13$ pre exercise to $1.0 \pm 0.13$ after four weeks of exercise implementation among study group compared to $(0.70 \pm 0.10)$ in the control group. Recommendations: A health teaching about Buerger Allen exercise should be carried out for all type II diabetic patients to improve their peripheral circulation. Besides, a colored booklet should be available and distributed to all diabetic patients.
\end{abstract}

Key words: Selected Range of Motion Exercise, Peripheral Circulation, and Type II Diabetes Patients.

\section{Introduction}

Diabetes mellitus (DM) has become a major chronic health problem worldwide and is defined as a group of metabolic disorder that is characterized by increasing the blood glucose level due to defect in the insulin secretion, insulin action, or both. Elevated level of blood glucose produces the classical symptoms of diabetes including polyuria, polydipsia, and polyphagia (Patidar, 2018 \& El Fattah et al, 2019).

Diabetes mellitus is classified into three types: type I, type II and gestational diabetes. Beta cell of pancreas is destroyed in type I diabetes (insulin-dependent diabetes mellitus) so that the body can't produce insulin. It represents about $10 \%$ of all diabetic cases and affect people before $40^{\text {th }}$ years of age, often in early adulthood or teenage years. On the other hand, type II diabetes occurs when the body does not produce enough insulin needed for the body functions or the cells in the body do not responde to insulin (insulin resistance). It affects about $90 \%$ of all cases of diabetes worldwide (Suresh Lal, 2016).

The third type of diabetes is the gestational diabetes (GDM) that affects pregnant women usually during the second and third trimesters of pregnancy and may be resolved after 


\section{Effect of Selected Range of Motion Exercise on Peripheral Circulation among Patients with Type II Diabetes Mellitus}

pregnancy. GDM occurs when the hormone produced by the placenta inhibits the insulin action (insulin resistance). Women with previous history of GDM are more risk for type II diabetes after the delivery by seven folds than women without (Moon et al., 2017).

Diabetes mellitus affects 463 million adults globally aged between 20-79 years and will be rised to 700 million by 2045 . Egypt is one of the 21 countries in Middle East and North Africa region (MENA) as 55 million people in the MENA region have diabetes and will be reached to108 million by 2045. As there were $8,850,400$ adults cases of diabetes in Egypt in 2019 (International Diabetes Federation, 2019).

The symptoms of diabetes vary based on blood glucose level. These symptoms include polyuria, polydipsia, polyphagia, unexplained weight loss, fatigue, irritability, blurred vision, slow wound healing, frequent infections, such as gums, skin or vaginal infections (Mayo clinic, 2018).

Diabetes including type II affects every organ of the body and is associated with life threating complications. These complications are divided into micro and macro vascular complications. Microvascular complications include diabetic retinopathy, neuropathy and nephropathy that result from damage of the small vessels within the microcirculation of the retina, neurons and kidney. Otherwise macrovascular complications are stroke, cardiovascular and peripheral arterial diseases that affect large blood vessels (Papatheodorou et al., 2016).

Peripheral arterial disease (PAD) is one of macrovascular associated diabetic complications. It is defined as an atherosclerotic narrowing of peripheral arteries of the legs, stomach, arms, and the head but more common in lower extremities arteries. Moreover PAD is considered a manifestation of atherosclerosis in major blood vessels such as coronary and cerebral arteries. It is not only contributor for initiation and aggravation of diabetic foot ulcer but also is an efficient precursor of cardiovascular mortality and morbidity by causing systemic vascular thrombosis that leads to cerebrovascular events and myocardial infarction (Thiruvoipati et al., 2015; Shukla et al., 2018 \& Arora, et al., 2019).

Diabetic complications can be prevented through well-structured preventive plan that include healthy diet, smoking cessation, weight reduction, foot care, psychological care, ophthalmological, dental, and podiatric referrals and range of motion exercises. One of the effective structured exercises is Buerger Allen exercise (American Diabetes Association, 2017).

Buerger Allen Exercise is one of the most common range of motion exercises that improves lower extremities perfusion among patients with type II diabetes through the development of collateral circulation in the legs using gravitational changes in positions that are applied to the smooth musculature of vessels and to the vascular bed. Gravity increases blood flow to the legs by emptying and filling the blood columns alternatively. This exercise is performed in three steps and prescribed for about $17-23$ minutes. The complete sequence is repeated three times per day (Change et al., 2016 ; Mellisha, 2016) .

\section{Significance of the Study}

Type II Diabetes is the most common forms of diabetes. Recent studies stated that Diabetes Mellitus increase the risk of peripheral vascular disease by two and four times. It is mentioned that Diabetes Mellitus is the main 


\section{Effect of Selected Range of Motion Exercise on Peripheral Circulation among Patients with Type II Diabetes Mellitus}

cause of more than half of nontraumatic lower limb amputation due to peripheral vascular disease. As every 30 seconds, a lower limb or part of a lower limb is lost somewhere in the world because of diabetes (Refaat et al., 2015; Mellisha, 2016; International Diabetes Federation, 2017).

There is a limited evidence related to the effect of Buerger Allen exercise on peripheral circulation among type II diabetic patients.

\section{Purpose of the Study}

The Purpose of the current study is to determine the effect of selected range of motion exercise (Buerger- Allen Exercise) on peripheral circulation among patients with type II diabetes mellitus

\section{Research Hypothesis:}

- Patients who practise Buerger Allen exercise (study group) will have higher total performance score than patients who don't (control group).

- Patients who apply Buerger Allen exercise (study group) will exhibit more improved peripheral circulation manifestations than control group patients.

\section{Operational definition:}

- Buerger Allen exercise is one of the most common range of motion exercises that helps to improve peripheral circulation among diabetic patients through using gravitational changes of positions to relieve symptoms of arterial insufficiency.

- Peripheral circulation is operationally defined as the oxygenated blood flow to lower extremity tissues through different arteries that will be assessed through assessing physiological measures such as foot temperature and capillary refill time as well as assessing the ratio of ankle blood pressure to brachial blood pressure.

\section{Methods}

\section{Research design:}

A Quasi-experimental research design was utilized in this study (study \& control group).

\section{Research Setting:}

The study was carried out in Outpatient Medical Clinic at Shebin El Kom Teaching Hospital.

\section{Sample:}

A consecutive sample of 100 adult patients were selected and divided alternatively into two equal groups: 50 patients for each group (study control).

\section{Instruments:}

Instrument I Structured interviewing questionnaire: It was developed by the researcher to assess baseline bio-sociodemographic data. It is comprised of two parts as the following:

Part one: Sociodemographic data: It was include information about patient's age, sex, level of education, occupation and marital status.....etc.

Part two: Medical data: It was include information about past and present medical history such as duration of illness, taken medication, previous diabetic ulcers or amputation, family history and previous surgery....etc.

II. Instrument II: physiological instrument: - It was be developed by the researcher to assess signs and symptoms of peripheral circulation impairment such as intermittent claudication, numbness and tingling of lower extremity, foot temperature, pedal pulse, skin changes and capillary 


\section{Effect of Selected Range of Motion Exercise on Peripheral Circulation among Patients with Type II Diabetes Mellitus}

refill time...etc (Foley et al., 2016 \&

Jameson et al., 2018)

III. Instrument III The anklebrachial pressure index (ABPI):- It was developed by Potier, et al., (2011) to assess peripheral arterial disease it is measured by the ratio of the blood pressure at the ankle to the blood pressure in the upper arm (brachium).

It is calculated by the following formula:

Maximum systolic ankle pressure

Maximum systolic brachial pressure

\section{Scoring system as a follow:-}

- ABPI is between (0.91-1.30) indicate normal index.

- ABPI is between (0.70-0.90) indicate mild occlusion.

- ABPI is between (0.40-0.69) indicate moderate occlusion.

- ABPI is $(<0.40)$ indicate severe occlusion.

- ABPI is (>1.30) indicate poorly compressible vessels.

Instrument IV: Observational checklist

It was be developed by the researcher to evaluate patients' performance of Buerger Allen exercise. It was include the exercises that should be done by the patients to be checked by the researcher if it practiced by the patients effectively or not.

Scoring system as a follow: - One mark was be given for performing each step in the exercise correctly. Zero mark was be given for performing each step in the exercise incorrectly or if it is not done. All marks will be collected and a percentage will be estimated.

- If the score of the checklist was $70 \%$ or more, it was indicate good performance.
- If the score was between $50 \%-70 \%$, it was indicate acceptable performance and if the score was less than $50 \%$, it was indicate poor performance

\section{Content validity:}

All instruments were tested for face and content validity by 5 experts in the field of Medical-Surgical Nursing Department Faculty of Nursing, Menoufia University. Modifications were done to ascertain relevance and completeness.

\section{Reliability of the instruments:}

All instruments were tested for reliability using test retest method to ascertain consistency: All instruments were tested using Cronbach's alpha test .The period between each test was two weeks. The reliability of instruments was done to determine the extent to which items in the instruments were related to each other by Cronbach's Co-efficiency Alpha for it $\operatorname{was}(r=0.91)$ for instrument I, 0.84 for instrument II, 0.84 on the right side and 0.77 on the left side for instrument III and 0.93 for instrument IV (Chongthawonsatid \& Dutsadeevettakui, 2017). So, it can be concluded that all instruments have adequate level of reliability.

Ethical Consideration A written approval from ethical and research committee was obtained to carry out the study then an official letter from Menoufia faculty of nursing was delivered to the responsible authorities of Shebin El Kom Teaching hospital (outpatient medical clinic) administrators and the head nurses of outpatient clinics to obtain written approval to conduct this study from them after explaining the aim of study. All patients were informed about the aim of the study and their rights that they were free to decide whether or not they would participate in the study. 


\section{Effect of Selected Range of Motion Exercise on Peripheral Circulation among Patients with Type II Diabetes Mellitus}

Then a written informed consent was obtained from each patient. Confidentiality was ensured by not sharing the information linked to the participants name with other individuals.

Pilot study: - A pilot study was conducted prior to data collection on $10 \%$ of the study sample (10 patients). This was performed to test the clarity and applicability of the instruments. Necessary modifications were done.

\section{Procedure:}

- An Official letter from the faculty of nursing was delivered to the responsible authorities of hospital (the hospital chief executive and the director of Outpatient Clinics) to obtain the approval to conduct this study .The letter contained an explanation of the purpose of the study.

- Data were collected over a period of 8 months from September, 2020 to May, 2021.

- Patients who agreed to participate in the study and fulfilled the inclusion criteria were interviewed individually by the researcher in outpatient medical clinic

- A consecutive sample of 100 adult patients with type II diabetes mellitus fulfilled the inclusion criteria were selected, randomly and alternatively divided into two groups; study group (I) perform Buerger Allen exercise along with routinely hospital care such as measuring blood glucose and blood pressure

- The study was conducted on four phases: Assessment, planning, implementation and evaluation phases as a following:

\section{Assessment phase:}

This phase took 20-30minutes for each subject of both group

During this phase the researcher interviewed each subject of both groups to collec base line data by using both tools as follow:

- The researcher assessed sociodemographic data using part one and two of instrument I.

- All subjects of both groups were assessed for peripheral circulation (intermittent claudication, numbness and tingling of lower extremity, foot temperature, pedal pulse, skin changes and capillary refill time) using both second and third instrument (physiological instrument and ankle brachial index).

- All subjects of study group were asked to perform Buerger Allen exercise and their performances were assessed by using instrument IV.

\section{Planning phase:}

A colored illustrative booklet with pictures was prepared by researcher including the information about:

- Diabetes Mellitus: Definition, types, causes or risk factors, clinical manifestations, complications and management

- Peripheral arterial disease: Definition, risk factors related diabetes, clinical manifestations, complications and prevention.

- Buerger allen exercise: Definition, importance and technique.

\section{Implementation phase:}

- The researcher conducted three teaching sessions of 30 minutes for each participant of group I.

- Each teaching session followed by a follow up session to reinforce the received information and answer any question and evaluate their performance of Buerger Allen exercise.

- Each session was conducted in the waiting area of the 


\section{Effect of Selected Range of Motion Exercise on Peripheral Circulation among Patients with Type II Diabetes Mellitus}

Outpatient Medical Clinic Using lecture and discussion.

- During follow up period (the researcher reinforced the participants by phone to assure their performance of educated exercise.

- The researcher distributed the prepared booklet for every subject of group I (study group) before starting session I.

- During the first session: Information about the diabetes definition, types, causes or risk factors, clinical manifestations, complication and management were illustrated.

- During the second session: patients received information about peripheral arterial disease definition, risk factors related to diabetes, clinical manifestations and complications.

- During the third session: instructions were given about Buerger Allen exercise definition, importance and technique.

\section{Evaluation phase:}

- Evaluation of all patients of both Evaluation of all subjects of both groups was carried out two weeks following the post second teaching session using all instruments except the first one.

- A comparison between both groups was carried out to determine the effect of Buerger Allen exercise on peripheral circulation among patients with type II diabetes

- Evaluation of all patients of both groups was carried out one month following the post second teaching session using all instruments except the first one

- A comparison between both groups was carried out to determine the effect of Buerger Allen exercise on peripheral circulation among patients with type II diabetes.

\section{Statistical analysis:}

The data collected were tabulated \& analyzed by SPSS (statistical package for the social science software) statistical package version 20 on IBM compatible computer.

Two types of statistics were done:

1. Descriptive statistics: were expressed as mean and standard deviation $(\mathrm{X}+\mathrm{SD})$ for quantitative data or number and percentage (No $\& \%$ ) for qualitative data.

\section{Analytic statistics:}

1) Pearson Chi-square test $\left(\chi^{2}\right)$ and Fisher Exact test: It is the test of significance used to study association between two qualitative variables.

2) Student t- test (parametric test): is a test of significance used for comparison between two independent groups of normally distributed quantitative varliables.

3) ANOVA test (parametric test): is a test of significance used for comparison between more than two independent groups of normally distributed quantitative variables.

4) Repeated measures ANOVA: is a test of significance used when we had a single line of data for each participant, with the repeated measures entered as separate variables on that same line (used for comparison between more than two related groups of normally distributed quantitative variables).

5) Spearman correlation: is a test of significance used for quantitative variables that were not normally 


\section{Effect of Selected Range of Motion Exercise on Peripheral Circulation among Patients with Type II Diabetes Mellitus}

distributed or when one of the variables is qualitative.

6) Post hoc tests are run to confirm where the differences occurred between groups, they are only run when we had an overall statistically significant difference in group means (i.e., a statistically significant one-way ANOVA result).

P-value at 0.05 was used to determine significance regarding:

- P-value > 0.05 to be statistically insignificant.

- $\mathrm{P}$-value $\leq 0.05$ to be statistically significant.

- P-value $\leq 0.001$ to be highly statistically significant.

\section{Results}

Table (1) Table (1) illustrates distribution of both study and control group regarding their demographic characteristics. It is observed about two thirds of both study and control groups $(60 \%$ and $66 \%$ respectively) had fifty years or more with a mean age $50.98 \pm 9.35$ years for study and $50.52 \pm 7.21$ years for control group.

Regarding sex, less than three quarters of both study and control groups (70\% and $74 \%$ respectively) were females. The majority of both them $(78 \%$ and $88 \%$ respectively) were married. As regard level of education, about half of the study group (56\%) and control group (48\%) were illiterate. In relation to occupation, about two thirds of both study group and control groups (64\% and 68\% respectively) were housewives.

There were no statistical significant difference between both a study and a control groups regarding almost all demographic characteristics.
Figure (1) presents that, pre exercise implementation, all subjects of study group $(100 \%)$ had poor performance score that was improved to good performance four weeks post exercise performance.

Figure (2) reveals that, less than two thirds of study group (62\%) and more than three fourths of control group (78\%) complained from pain and intermittent claudication pre exercise implementation. While two and four weeks post exercise implementation, a highly significant improvement among study group was observed $(22 \%$ and $4 \%$ respectively) compared to $(80 \%$ and $80 \%$ of control group.

Figure (3): shows that almost all subjects of both study and control groups (100\% and 98\% respectively) had delayed capillary refill time pre exercise implementation while two and four weeks post exercise implementation, $14 \%$ and $4 \%$ of study group respectively still had delayed capillary time compared to $100 \%$ and $100 \%$ of control group.

Table (2): illustrates mean and standard deviation of Ankle Brachial Pressure Index scores among study and control groups pre, two and four weeks post Buerger Allen exercise. This table shows that, pre exercise the mean scores of right ankle brachial index in the study group was $0.74 \pm 0.06$ that was improved to $0.91 \pm 0.12$ and1.0 \pm 0.13 two and four weeks post exercise implementation respectively versus $0.71 \pm 0.12, \quad 0.72 \pm 0.12$ and $0.71 \pm 0.11$ of the control group. While in left ankle brachial index, the mean score of left ankle brachial index in the study pre exercise implementation was $0.72 \pm 0.13$ that was improved to $0.87 \pm 0.13$ and $1.01 \pm 0.12$ two and four weeks post exercise implementation respectively versus $0.70 \pm 0.10$, $0.71 \pm 0.10$ and $0.70 \pm 0.10$ in the control group. There were highly statistical significant difference between both 


\section{Effect of Selected Range of Motion Exercise on Peripheral Circulation among Patients with Type II Diabetes Mellitus}

study and control groups regarding the mean scores of right and left ABPI two weeks and four weeks post exercise implementation.

Figure (4) illustrates that none of both study and control groups $(0 \%)$ had normal ankle brachial pressure index in right side pre exercise implementation, while two and four weeks post exercise implementation respectively $42 \%$ and $80 \%$ of study group had normal index compared to $(0 \%)$ of control group.

Figure (5) this figure illustrates that none of both study and control groups $(0 \%)$ had normal ankle brachial pressure index in left side pre exercise implementation, while two and four weeks post exercise implementation respectively $40 \%$ and $84 \%$ of study group had normal index compared to $0 \%$ and $4 \%$ of control group.

Table (3) presents that there was significant positive correlation between mean performance score of Buerger Allen exercise and both right and left ankle brachial index two weeks post exercise. While four weeks post exercise, there was a highly significant positive correlation between mean performance scores of Buerger Allen exercise and right ankle brachial pressure index and a significant positive correlations between mean performance scores of Buerger Allen exercise and left ankle brachial pressure index.

\section{Results:-}

Table (1): Distribution of both a study and a control groups regarding their demographic

characteristics

\begin{tabular}{|c|c|c|c|c|c|c|}
\hline \multirow{3}{*}{ Demographic characteristics } & \multicolumn{4}{|c|}{ Studied groups } & \multirow{3}{*}{$\chi^{2}$} & \multirow{3}{*}{$P$ value } \\
\hline & \multicolumn{2}{|c|}{$\begin{array}{c}\text { Study group } \\
\qquad(\mathrm{n}=\mathbf{5 0})\end{array}$} & \multicolumn{2}{|c|}{$\begin{array}{c}\text { Control group } \\
(n=50)\end{array}$} & & \\
\hline & NO. & $\%$ & NO. & $\%$ & & \\
\hline $\begin{array}{l}\text { Age (years): } \\
\text { Mean } \pm \text { SD } \\
\text { Range }\end{array}$ & \multicolumn{2}{|c|}{$\begin{array}{l}50.98 \pm 9.35 \\
30.0-60.0\end{array}$} & \multicolumn{2}{|c|}{$\begin{array}{l}50.52 \pm 7.21 \\
37.0-60.0 \\
\end{array}$} & $\begin{array}{c}\mathbf{t}-\text { test }= \\
0.27\end{array}$ & 0.78 \\
\hline $\begin{array}{l}\text { Age categories (years): } \\
30-<40 \\
40-<50 \\
50-60\end{array}$ & $\begin{array}{c}6 \\
14 \\
30\end{array}$ & $\begin{array}{l}12.0 \\
28.0 \\
60.0\end{array}$ & $\begin{array}{c}2 \\
15 \\
33\end{array}$ & $\begin{array}{c}4.0 \\
30.0 \\
66\end{array}$ & 5.64 & 0.13 \\
\hline $\begin{array}{l}\text { Gender: } \\
\text { Male } \\
\text { Female }\end{array}$ & $\begin{array}{l}15 \\
35\end{array}$ & $\begin{array}{l}30.0 \\
70.0\end{array}$ & $\begin{array}{l}13 \\
37\end{array}$ & $\begin{array}{l}26.0 \\
74.0\end{array}$ & 0.19 & 0.65 \\
\hline $\begin{array}{l}\text { Marital status: } \\
\text { Single } \\
\text { Married } \\
\text { Widowed } \\
\text { Divorced }\end{array}$ & $\begin{array}{l}0 \\
39 \\
11 \\
0\end{array}$ & $\begin{array}{c}0.0 \\
78.0 \\
22.0 \\
0.0\end{array}$ & $\begin{array}{c}3 \\
44 \\
2 \\
1\end{array}$ & $\begin{array}{c}6.0 \\
88.0 \\
4.0 \\
2.0\end{array}$ & 10.53 & $\stackrel{0.01}{\mathrm{~S}}$ \\
\hline $\begin{array}{l}\text { Education level: } \\
\text { Illiterate } \\
\text { Primary } \\
\text { Secondary } \\
\text { University }\end{array}$ & $\begin{array}{c}28 \\
5 \\
12 \\
5\end{array}$ & $\begin{array}{l}56.0 \\
10.0 \\
24.0 \\
10.0\end{array}$ & $\begin{array}{c}24 \\
5 \\
17 \\
4\end{array}$ & $\begin{array}{c}48.0 \\
10.0 \\
34.0 \\
8.0\end{array}$ & 1.28 & 0.73 \\
\hline $\begin{array}{l}\text { Occupation: } \\
\text { Manual Work } \\
\text { Administrative work } \\
\text { Housewife } \\
\text { Not work }\end{array}$ & $\begin{array}{c}5 \\
6 \\
32 \\
7\end{array}$ & $\begin{array}{l}10.0 \\
12.0 \\
64.0 \\
14.0\end{array}$ & $\begin{array}{c}9 \\
4 \\
34 \\
3\end{array}$ & $\begin{array}{c}18.0 \\
8.0 \\
68.0 \\
6.0\end{array}$ & 3.20 & 0.36 \\
\hline
\end{tabular}

$\mathrm{S}=$ significant $\leq 0.05$ 


\section{Effect of Selected Range of Motion Exercise on Peripheral Circulation among Patients with Type II Diabetes Mellitus}

Figure (1): Distribution of total performance score of Buerger Allen exercise among the study group pre, two and four weeks post exercise implementation

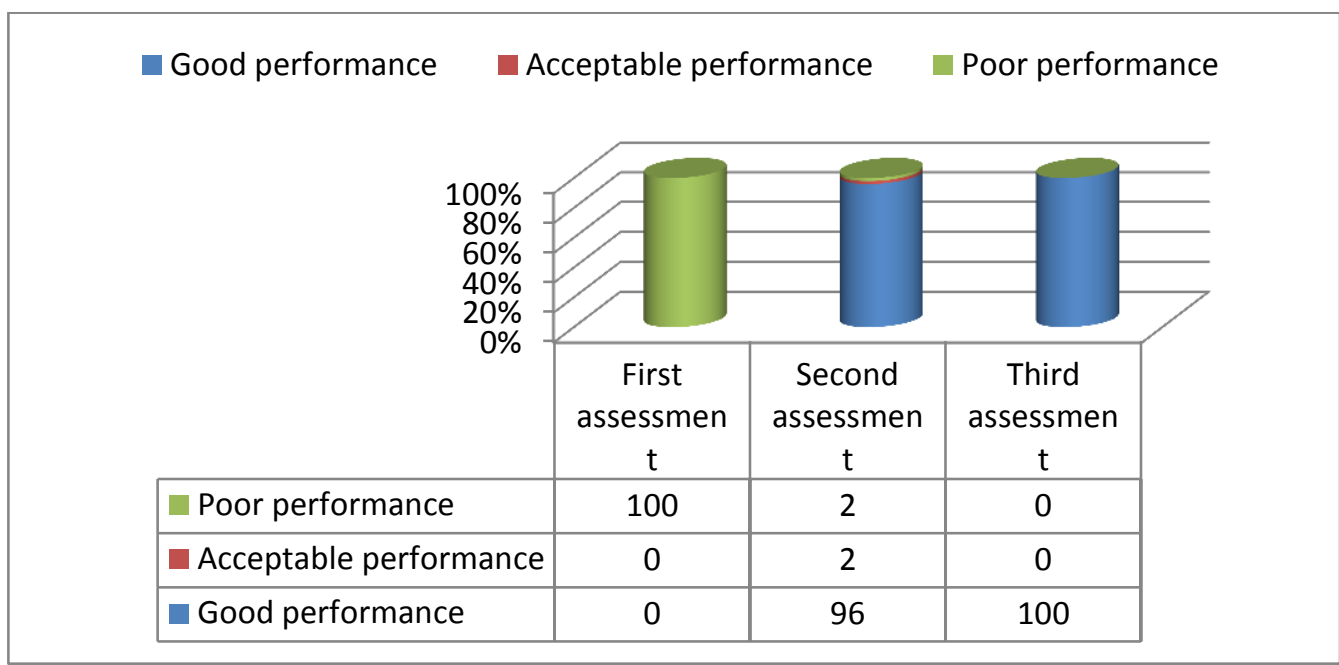

Figure (2) Distribution of study and control groups regarding pain and intermittent claudication pre, two and four weeks post Buerger Allen exercise

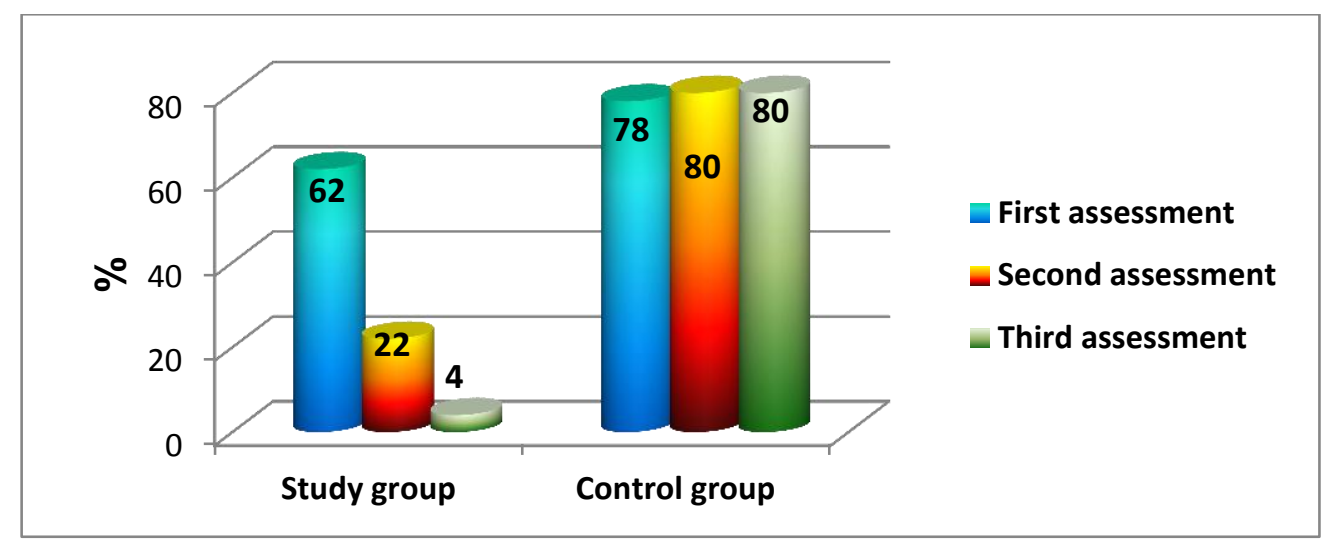

Figure (3) Distribution of both study and control group regarding capillary refill time pre, two and four weeks post exercise implementation

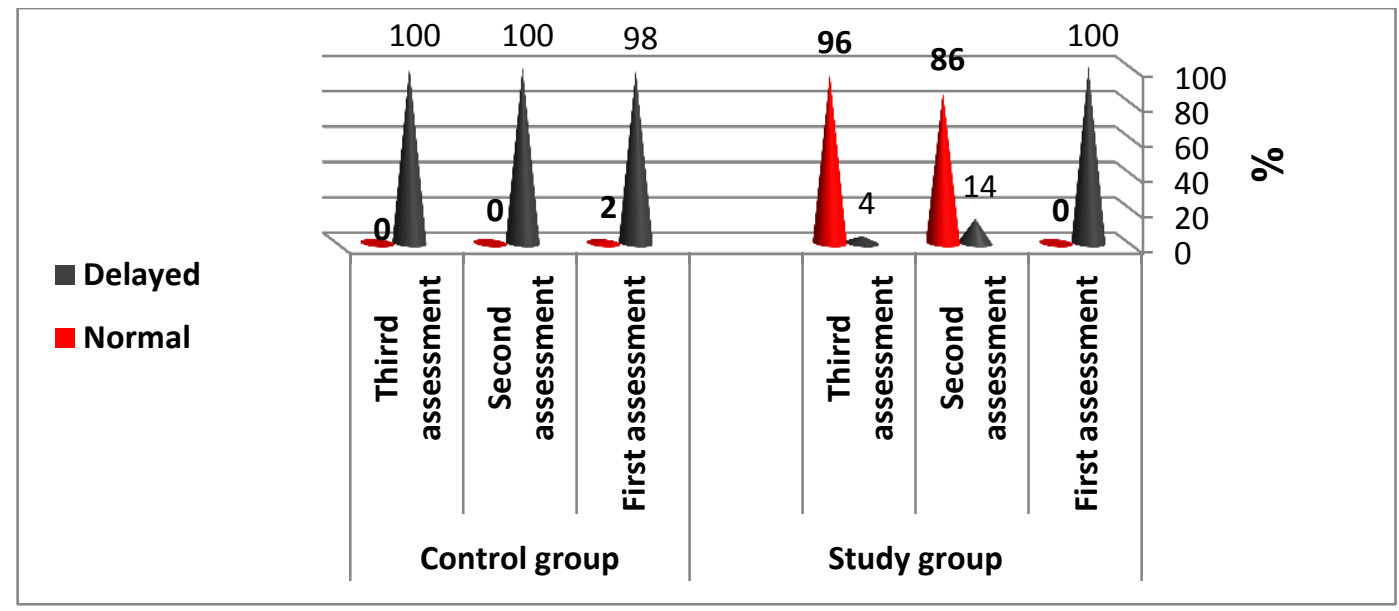

$P 1=1.0 \quad P 2<0.001$ highly significant $\quad P 3<0.001$ highly significant 


\section{Effect of Selected Range of Motion Exercise on Peripheral Circulation among Patients with Type II Diabetes Mellitus}

Table (2): Mean and standard deviation of Ankle Brachial Pressure Index score among study and control groups pre, two and four weeks post Buerger Allen exercise implementation

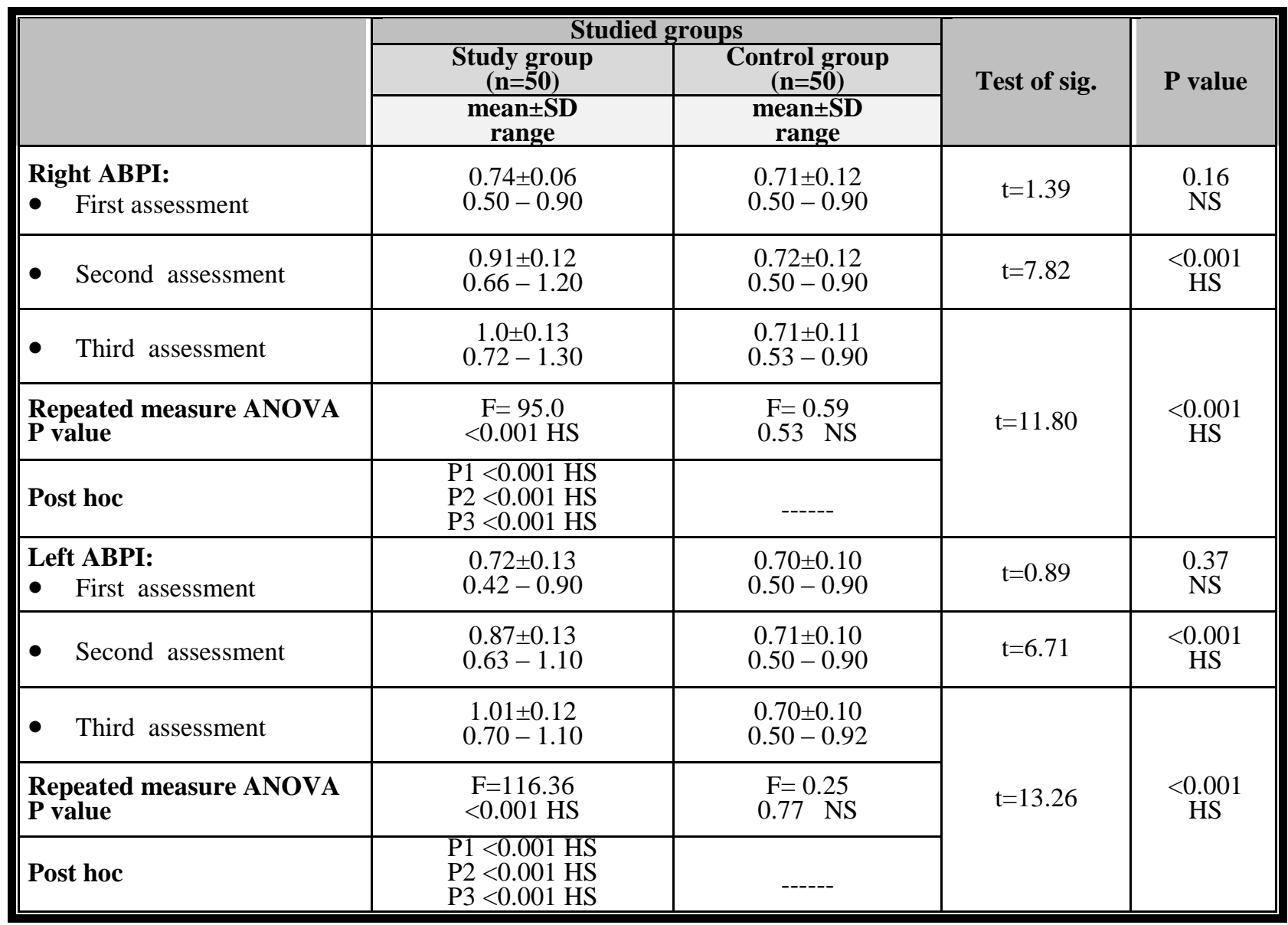

P1: comparison of first measure with second measure

P2: comparison of first measure with third measure

P3: comparison of second measure with third measure

Figure (4) Distribution of Ankle Brachial Pressure Index scores among study and control groups pre, two and four weeks post Buerger Allen exercise implementation in the right side

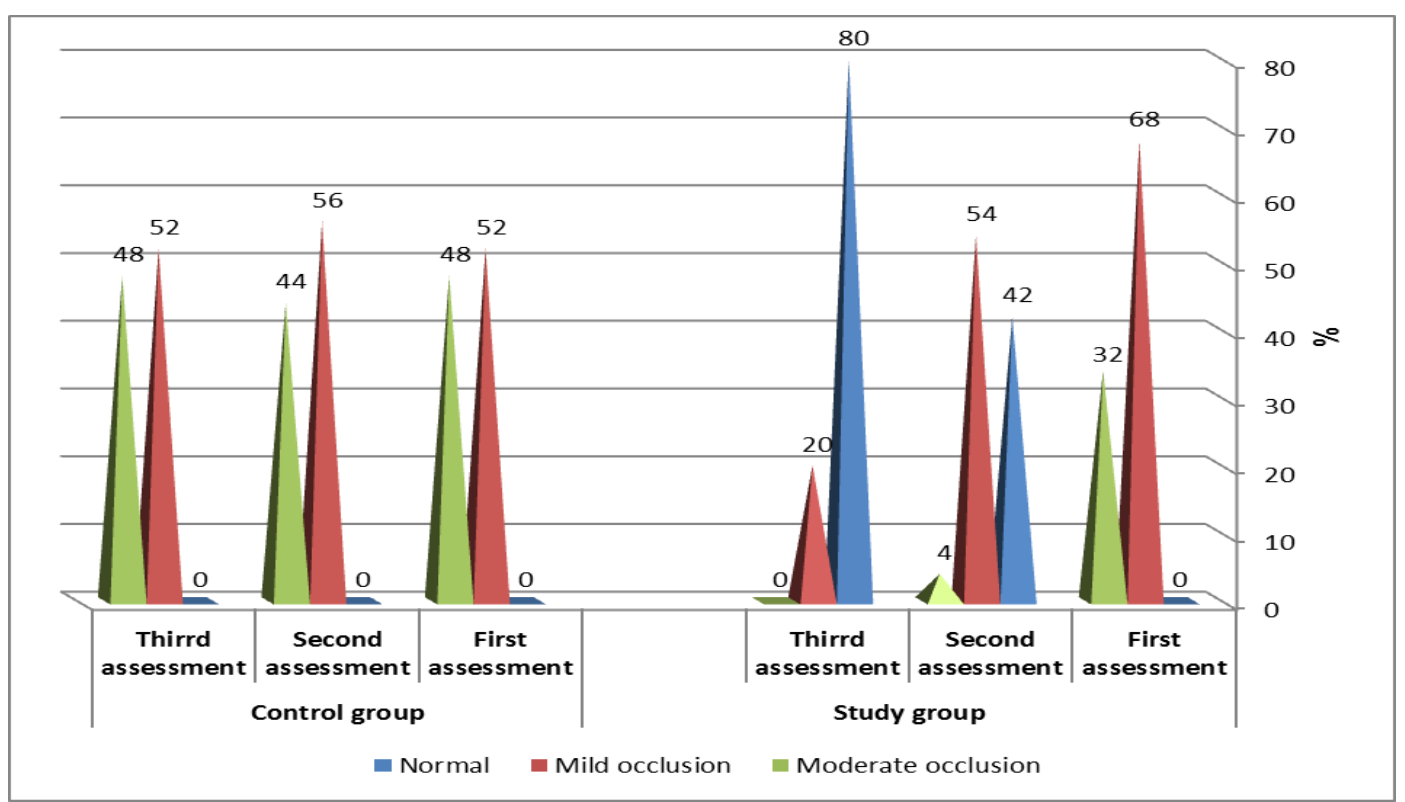




\section{Effect of Selected Range of Motion Exercise on Peripheral Circulation among Patients with Type II Diabetes Mellitus}

Figure (5) Distribution of Ankle Brachial Pressure Index scores among study and control groups pre, two and four weeks post Buerger Allen exercise implementation in the left leg

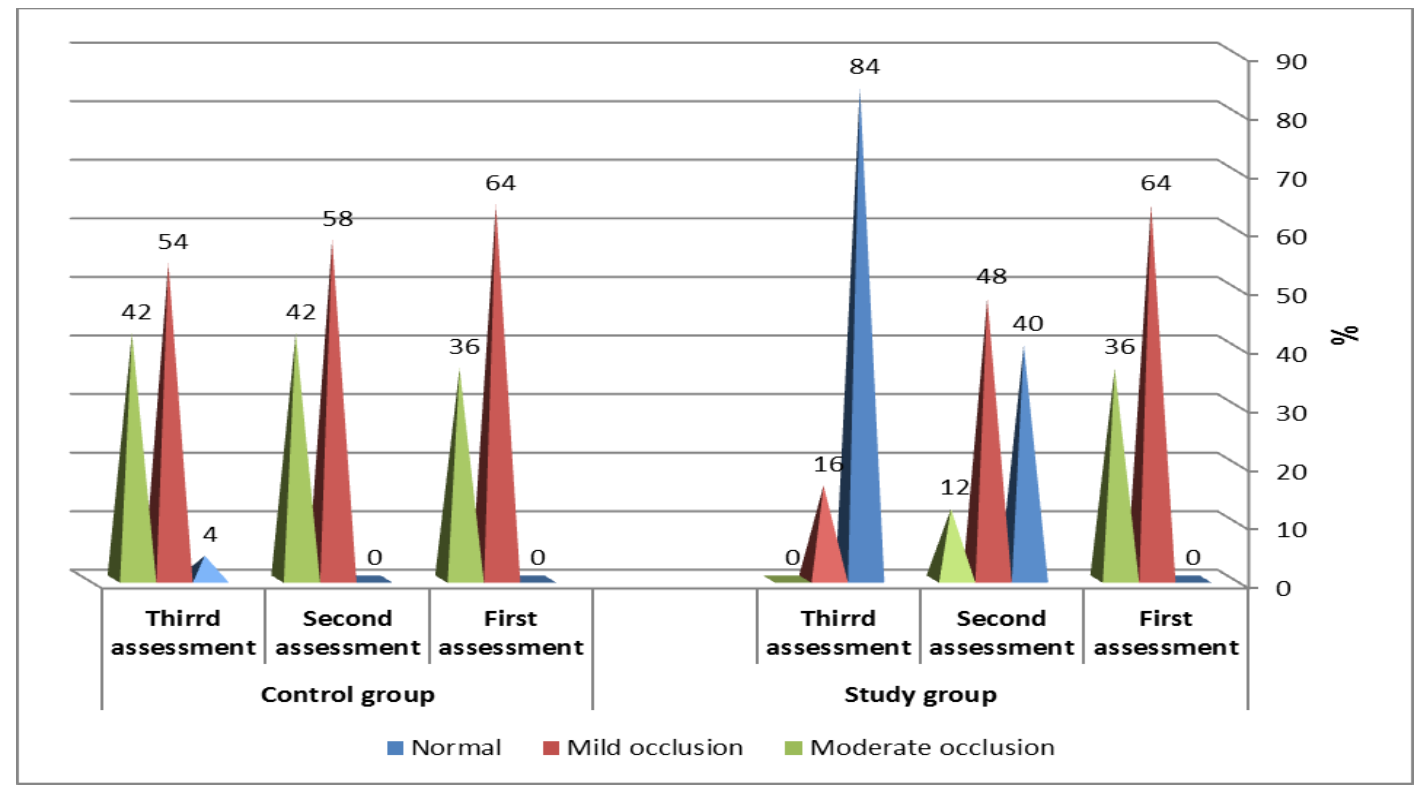

Table (3) Correlation between patients' performance of Buerger Allen exercise and of Ankle

Brachial Pressure Index of the study group two and four weeks post exercise implementation

\begin{tabular}{|c|c|c|c|c|}
\hline & \multicolumn{2}{|c|}{$\begin{array}{l}\text { patients' performance of Buerger } \\
\text { Allen exercise at second week }\end{array}$} & \multicolumn{2}{|c|}{$\begin{array}{l}\text { patients' performance of Buerger } \\
\text { Allen exercise at fourth week }\end{array}$} \\
\hline & $\begin{array}{c}c r \\
\text { (spearman`s } \\
\text { correlation } \\
\text { coefficient) } \\
\end{array}$ & $P$ value & $\begin{array}{c}\mathrm{R} \\
\text { (spearman`s } \\
\text { correlation } \\
\text { coefficient) }\end{array}$ & $P$ value \\
\hline Right ABPI (2 weeks) & 0.37 & $0.007 \quad \mathrm{~S}$ & & \\
\hline Left ABPI ( 2 weeks) & 0.31 & $0.02 \mathrm{~S}$ & & \\
\hline Right ABPI (4 weeks) & & & 0.52 & $<0.001 \quad \mathrm{HS}$ \\
\hline Left ABPI (4 weeks) & & & 0.31 & 0.02 \\
\hline
\end{tabular}

\section{Discussion}

Peripheral arterial disease increases the risk for claudication, ischemic ulcers, gangrenes and possible amputation. As about $15-40 \%$ people with PVD have a diminished ability to perform daily activities. Most of these complications can be prevented through a healthy life style such as staying healthy, maintaining weight, taking medications as prescribed and adhering to exercise regimen (Bhuvaneshwari \& Tamilselvi, 2018).

One of these exercises is the Buerger Allen that stimulate the development of collateral circulation in the legs by using gravitational changes in positions that are applied to the smooth musculature of vessels and the vascular bed. Gravity helps to empty and to fill the blood columns alternatively, which can eventually increase transmission of blood through them. In addition, it promotes wound healing and improves peripheral neuropathy symptoms among diabetic patients (Hassan et al., 2020).

Hence the aim of the present study was to determine the effect of selected range of motion exercise (Buerger 


\section{Effect of Selected Range of Motion Exercise on Peripheral Circulation among Patients with Type II Diabetes Mellitus}

Allen) on peripheral circulation among patients with type II diabetes mellitus.

\section{Performance of Buerger Allen exercise:}

The current study finding reported that all subjects of both study and control group had bad performance score pre intervention but two and four weeks post exercise implementation there were significant improvement of performance score of study group while control group remained with poor performance score and these results supported the first hypothesis of the current study which stated that Patients who practice Buerger Allen exercise (study group) will have higher total performance score than patients who don't (control group).

Manifestation of peripheral circulation impairment The finding of the present study revealed that almost all studied subjects of both groups complained of manifestations of impairment in the peripheral circulation pre exercise but after two and four weeks of Buerger Allen exercise implementation, there were highly statistical significant improvements in signs and symptoms among study group than control group. These findings supported the second hypothesis that stated patients who apply Buerger Allen exercise will exhibit more improved peripheral circulation manifestations than control group patients.

These findings was consistent with the studies done by Hassan et al., (2020) and Mohammed et al., (2021) who revealed that there were highly statistically significant improvements in pain level among the study group after six weeks of Buerger Allen exercise implementation. Moreover these findings were in agreement with study done by El Sayed et al., (2021) who showed that there was statistically significant improvement in the lower extremity perfusion feelings such as numbness, tingling, burning, crawling, sensitivity to touch and water, open sores and pain during walking.

Regarding ankle brachial index score pre, two and four weeks after Buerger Allen exercise implementation, the present study results showed that there were no statistical significant differences between both groups pre exercise for both right and left limbs but there were highly statistically significant improvements of ABPI mean scores between study and control groups after two and four weeks of exercise implementation in both limbs These findings were consistent with the studies done by El Fatah et al., (2019) who revealed that there were highly statistical significant difference between the mean score of ABI of both legs post Buerger Allen exercise than pre exercise and also there was an agreement with Kumari et al., (2019) who revealed that there were highly statistically significant improvement in the mean scores of ABI in both limbs post exercise among the study group than the control group. Moreover Radhika et al., (2020) revealed that there is a significant improvement in the mean score of ABI among the studied subjects after applying Buerger Allen exercise.

Additionally, El Sayed., et al., (2021) stated that there was a highly statistically significant difference between pre exercise and five days post exercise regarding the mean scores of ABI in both legs. Also there were statistically significant differences regarding the mean scores of ABI in both legs post five and fifteen days of Buerger Allen exercise implementation.

Moreover, the result of the current study was congruent with the study done by Mohammed et al., (2021) which showed that there was a highly statistically significant improvement of 


\section{Effect of Selected Range of Motion Exercise on Peripheral Circulation among Patients with Type II Diabetes Mellitus}

ABI among studied subjects after six weeks of applying Buerger Allen Exercise. The improvement from the researcher's opinion may be due to sufficient period of exercise performance that help in promoting the development of collateral circulation in lower extremity that improve the peripheral blood flow. Also these finding supported the second study hypothesis.

Correlation between patients performance of Buerger Allen exercise and ankle brachial pressure index:

There were significant positive correlation between performance of Buerger Allen exercise and mean scores of ABPI in both limbs at two weeks post exercise among study group. While after four weeks of exercise there were highly statistically significant correlation between performance and mean scores of ABPI in both limbs. From the researcher's point of view, the bad performance before intervention demonstrated the patient's need for education about exercise performance while after implementation of the exercise increase after explaining the benefit of the exercise on the peripheral circulation was shown.

\section{Conclusions:}

Based on the findings of this study, it can be concluded that:

- Buerger Allen exercise is an effective nursing intervention for improving peripheral circulation among patients with type II Diabetes Mellitus.

\section{Recommendations:}

Based on the findings of the present study, the following recommendations are derived and suggested:

- An assessment of peripheral circulation should be considered as an essential and routine care for patients with type II Diabetes Mellitus.

- Supervised health teaching regarding Buerger Allen exercise should be given for patients with type II diabetes mellitus to control peripheral arterial impairment.

- A colored illustrative booklet should be available and distributed to all diabetic patients. It should include knowledge about diabetes, its complications and importance of Buerger Allen exercise to improve peripheral circulation.

\section{Recommendation for further} research:

- A similar study can be replicated at different setting and on large sample to allow greater generalization of the findings.

\section{References}

American Diabetes Association. (2017). Standards of Medical Care in Diabetes Abridged for Primary Care Providers. Clinical Diabetes Journal; 35 (1): 5-26

Arora, E., Maiya, A., Devasia, T., Bhat, R. \& Kamath, G. (2019). Prevalence of peripheral arterial disease among Type II diabetes mellitus in coastal Karnataka "Diabetes and Metabolic Syndrome'. Clinical Research and Reviews; 13 (2): 1251-3.

Bhuvaneshwari, S., \& Tamilselvi, S. (2018). A study to assess the Effectiveness of Buerger Allen exercise on lower extremity perfusion among patients with type 2 diabetes mellitus in Saveetha Medical College and Hospital in Chennai. International Journal of Advance Research and Development; 3(9):15-20.

Chang, C., Chen, M., Shen, J., Lin, Y., Hsu, W., \& Lin, B. (2016). A quantitative real time assessment of Buerger exercise on dorsal foot skin circulation in patients with 


\section{Effect of Selected Range of Motion Exercise on Peripheral Circulation among Patients with Type II Diabetes Mellitus}

diabetic foot. Medicine Journal; 95 (46): $1-5$

El Fattah, H., Garas, A., Hanna, N. \& El Sayed, N. (2019). Effect of Buerger Exercise on improving peripheral circulation of the lower extremities among patients with Type II Diabetes Mellitus at selected university hospital-Egypt. Indian Journal of Public Health Research \& Development; 10 (6): 692-7

El Sayed, R., Abd Salam, S., \& El Metawaly, R. (2021). Effect of Buerger Allen Exercise on lower extremity perfusion among patients with type II Diabetes Mellitus. Egyptian Journal of Health; 12 (2): 555-72

Foley, T., Armstrong, E., \& Waldo, S. (2016). Contemporary evaluation and management of lower extremity peripheral artery disease. Heart Journal; 102(18):1436-41.

Hassan, Z., Bader El Din, S., \& El Rasek, A. (2020). Impact of Buerger Allen Exercise on improving selected clinical features of peripheral vascular disease among diabetic patients. Journal of Nursing and Health science; 9(2): 4-13

International Diabetes Federation. (2017). Diabetes facts and figures and complication. Diabetes atlas. Global fact sheet pdf. 8th ed. Brussels, Belgium. https://www.idf.org/aboutdiabetes /what-isdiabetes/factsfigures.html.

International Diabetes Federation. (2019). Diabetes facts and figures. Diabetes atlas.9th ed. Brussels, Belgium. Available at https://www.idf.org/aboutdiabetes /what-is-diabetes/factsfigures.html

Jameson, J., Fauci, A., Kapser, D., Hauser, S., Longo, D., \& Loscalzo, J. (2018). Harrison's Principles of Internal Medicine. 20th ed. Mc-Graw Hill, USA. 27884

Kumari, A., Rai, K., Kumari, V., \& Sarin, J. (2019). A Study to assess the Effectiveness of Buerger Allen on foot perfusion among patients with Diabetes Mellitus admitted in selected Hospital of Ambala, Haryana. International Journal of Health Science and Research; 9(1): 112-9

Mayo clinic. (2018). Diabetes. Symptoms and causes. Available at

https://www.mayoclinic.org/disea sesconditions/diabetes/symptomscauses/syc-20371444. Retrieved on March 2020.

Mellisha, S. (2016). Effectiveness of Buerger Allen exercise on lower extremity perfusion and pain among patients with type II diabetes mellitus in selected hospital. International Journal of Science and Research; 5(7):1822-6 Mohammad, I., Fahim, E., \& Heggy, E. (2021). Impact of Buerger Allen exercise on foot perfusion and pain level for Diabetic patients risk with peripheral arterial disease. Assiut Scientific Nursing Journal; 9(24):170-81

Moon, J., Kwak, S. \& Jang, H. (2017). Prevention of Type II diabetes mellitus in women with previous gestational diabetes mellitus. Korean Journal of Internal Medicine; 32 (1): 26-41

Papatheodorou, K., Papanas, N., Banach, M., Papazoglou, D. \& Edmonds, M. (2016). Complications of diabetes. Journal of Diabetes Research; 1: 1-3

Patidar, V. (2018). A study to assess the Effectiveness of Burger Allen Exercise on improving peripheral circulation among Type II diabetes mellitus patients in selected hospitals of Nadiad City. Clinical Practice Journal; 15(6): 895-900 


\section{Effect of Selected Range of Motion Exercise on Peripheral Circulation among \\ Patients with Type II Diabetes Mellitus}

Radhika, J., Poomalai, G., Nalini, S., \& Revathi, R. (2020).Effectiveness of Buerger Allen exercise on lower extremity perfusion and peripheral neuropathy symptoms among patients with Diabetes Mellitus. Iranian Journal of Nursing and Midwifery Research; 25(4): 291

Refaat, H., Mohamed, E., Nagy, A., \& Osama, H. (2015). Epidemiology of and risk factors for type II diabetes in Egypt. Annals of Global Health; 81(6): 815-20.

Shukla, V., Fatima, J., Soliman, A., M. \& Garg, A. (2018). A study of
Prevalence of peripheral arterial disease in Type II diabetes mellitus patients in a teaching hospital. The Journal of the Association of Physicians of India; 66 (5): 57-60

Suresh Lal, B. (2016). Public Health Environment and Social Issues in India. 1st ed. Serials publications, India. 55-68

Thiruvoipati, T., Kielhorn, C., \& Armstrong, E. (2015). Peripheral artery disease in patients with diabetes: $\quad$ Epidemiology, mechanisms, and outcomes. World Journal of Diabetes; 6(7): 961-9. 